\title{
Schizophrenia in Croatia: interregional differences in prevalence and a comment on constant incidence
}

\author{
Z Folnegović, V Folnegović-Šmalc
}

\begin{abstract}
Study objective-The aim was to examine why differences exist in schizophrenia prevalence and risk in some areas of Croatia, when schizophrenia incidence rates do not appear to vary.

Design-Areas differing by schizophrenia admission rates in patients born in 1953 and admitted by the age of 31 years are compared using a number of indicators relating both to general population characteristics and to those of schizophrenic cases in these populations.
\end{abstract}

Setting-The study covers the whole of Croatia (4 601469 inhabitants, 1981 census).

Subjects-By the age of 31 years, out of 80445 individuals born in Croatia in 1953, 464 were admitted for and diagnosed as having schizophrenia.

Main results-Admission risk rates are higher in those parts of Croatia where emigration rates are high and lower where immigration rates are high. There is also a positive correlation with schizophrenia prevalence and manic depressive psychosis rates. There is a negative correlation with age of onset of schizophrenia and with schizophrenic reproduction rates. In the study areas, hospital incidence rates are not significantly different.

Conclusions-Economic migration and negative selection in the domestic population are likely to be the most significant factors leading to differences in schizophrenia prevalence. The approximately equal incidence rates in the population, with different prevalence and admission risks, are linked to differences in the disease onset among schizophrenics with a positive family history for this condition. In other words, these patients, when part of the population with a greater prevalence and a greater hereditary loading, experience the onset more often at an earlier age. Thus they have a lower reproduction rate than in a population with a lower prevalence and a lower hereditary loading. Thus incidence rates in populations with different prevalences and different hereditary loads are maintained roughly equal over generations.

Already at the beginning of this century the prevailing view was that the northwest territory of Croatia, ie, the Istrian Peninsula (Subregion 3, fig 1) and Croatian Littoral (Subregion 7) were affected by a higher prevalence of mental disease than the rest of Croatia. Initially, this was founded on data showing a far larger number of psychiatric hospital beds in those areas than in other parts of Croatia. ${ }^{12}$ The first hospital statistics for 19271932 also indicated higher mental hospital case rates found for patients born in this part of Croatia. $^{3}$ Furthermore, 1959/60 psychiatric facilities' discharge data, as well as the data concerning those patients found on the hospital census date of 15 August 1962, indicated that schizophrenia admission rates in the populations of Istria and Croatian Littoral (study area) were nearly twice as high as in the rest of Croatia (control area). ${ }^{145}$

The conviction that there is a higher prevalence of mental cases in northwestern Croatia has stimulated epidemiological field studies. As early as the early 1930s Geratovic, ${ }^{6}$ carried out a study of schizophrenia heredity on the island of Krk. In the 1950s the Yugoslav Academy of Science and Art conducted an investigation on the health, social, and cultural conditions on the island of Susak, carrying out a psychiatric examination of the island's population as well. In a relatively small population characterised by autochthonism as well as by long standing intensive emigration to the USA, a prevalence of $1.1 \%$ and $0.6 \%$ was established for schizophrenia and manicdepressive psychoses, respectively. ${ }^{7}$ In the 1964 66 period surveys were done of the prevalence of psychoses in four communities in three different areas in Croatia. In all, 71015 inhabitants aged 20-64 years were covered, with the highest schizophrenia (300 ICD-7) and total functional psychoses (300-303 ICD-7) rates revealed in the Labin community, Istria (study area), and the lowest in the Popovača-Kutina community, inland Croatia (subregion 8: Sisak, fig 1). ${ }^{89}$ Thus these results also support the hypothesis that there is a higher prevalence of psychoses in the study area than in other areas.

In order to verify the hypothesis that the prevalence of psychoses in the populations of Istria and Croatian Littoral (study area) is higher than in other areas in Croatia (control area), surveys were done from 1969-1972 with regard to the prevalence of psychoses by using a representative sample of study and control area populations (PL 48002 280-2 Differential Rates of Psychoses in Croatia project). ${ }^{10-12}$ In 47 clusters chosen at random within the study area, a total of 11172 persons aged 20-64 years were examined versus 12582 in 48 control area clusters. The rate for functional psychoses in the study area was found to be 7.3 per 1000 , and 3.8 per 1000 in the control area. These data indicated that the two populations were different with 
respect to the presence of functional psychoses at greater than 0.05 level of confidence. (The rates for schizophrenia were found to be 5.9 per 1000 in the study area and 3.3 per 1000 in the control area.) The rates for functional psychoses in both sexes are significantly higher in persons over 40 years of age. ${ }^{13} 14$ Like earlier studies based on different sources of information and diagnostic criteria, this has also confirmed the hypothesis of a longer term higher prevalence of mental cases in northwestern Croatia.

In 1962, Croatia's psychiatric case register (CPCR) (see Methods in Folnegovic et al ${ }^{15}$ ) was established. The collection of data on Croatian schizophrenic hospital inpatients has been continuous and uniform ever since. The operation of the register also made it possible to gain insight into the first admission rates (hospital incidence), thus enabling the phenomenon to be monitored by regions and periods. For example, an analysis of CPCR information for 1971 revealed the age standardised annual hospital incidence rate for the population of Istria and Croatian Littoral (study area) to be 0.18 per 1000 , which is slightly lower than in the rest of Croatia (control area) where it amounted 0.21 per $1000 .^{16}$ Based on a comparative analysis of changes in case admission rates, hospital incidence rates and schizophrenia mortality in that period, it was concluded over the years the difference in schizophrenia prevalence between the study and control area populations was diminishing.

Despite the difference in and changeability of schizophrenia prevalence in some areas, no greater change occurred in the hospital incidence rate within the Croatian population (4601 469 inhabitants, 1981 census). ${ }^{15}$ On the contrary, it appeared that the genuine incidence rate of schizophrenia had not changed significantly, and it was also found to be about equal in the male and female population. The question remains as to which factors maintain the constant rate of

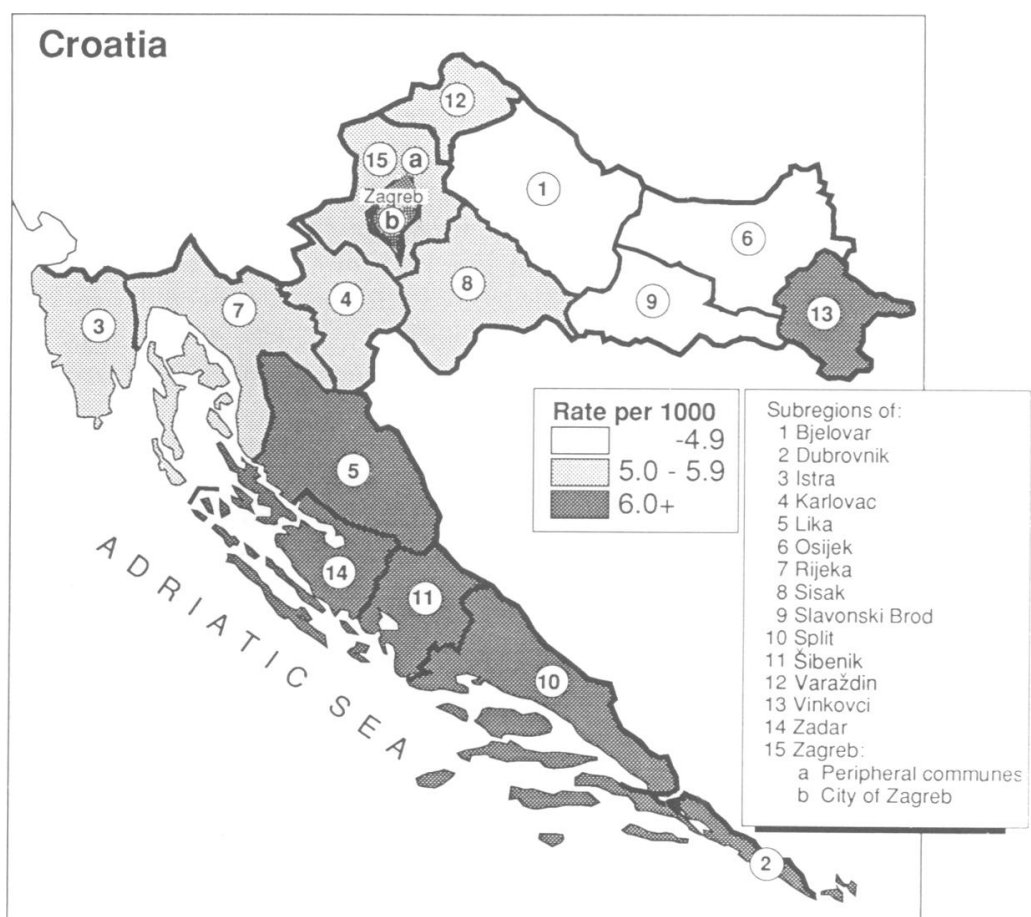

Figure 1 Admission risk up to the age of 31 years for schizophrenia cases born in 1953 in different subregions of Croatia incidence. The aim of the present study was formulated accordingly: it is an attempt to understand these factors on the basis of a comparative analysis of CPCR and relevant epidemiological data from studies completed in Croatia.

\section{Methods}

Information on the risk of developing schizophrenia for people born in some parts of Croatia constitutes the backbone of this study; the risk of the disease development is expressed in number of cases per 1000 births.

The CPCR, which has been recording all the schizophrenia admissions in the Republic of Croatia since 1962, is the source of information on affected individuals. The records for each case include community (the smallest administrative unit) of birth and year of birth, which made it possible to analyse the case distribution according to these characteristics as well.

The collection of data on births (like other vital events) has only become regular in this country since 1950. Birthplace is registered according to the place of permanent residence of the mother and shown according to administrative division units existent at the time of birth. Since a census was undertaken in 1953 (Vital Statistics for 1953, Federal Bureau of Statistics, Belgrade, 1956), the 1953 births were used in the present study to calculate the risk of schizophrenia. In view of the change in the administrative division of the territory of Croatia at more recent censuses, the 1953 births figures were corrected so as to comply with the new division, according to which the patient's place of birth is recorded by the CPCR as well. Taking into account the still high infant mortality in this country in those days, infant deaths were subtracted from the live newborn total before calculating the schizophrenia risk rate.

Consequently, of all schizophrenics admitted to hospital during the 1962-1984 period and recorded by CPCR, those born in 1953 in a particular subregion (association of communities) of Croatia were identified. Relating this figure to 1000 births in the subregion produced the socalled risk rate for a schizophrenic case to be admitted to hospital by the age of 31 years or "admission risk" as used here.

In order to note the correlation between the admission risk and other vital events, live births per 1000 inhabitants, infant deaths per 1000 live births, and stillbirths per 100 live births in 1953 in Croatian subregions were processed.

The subregions analysed were grouped into three areas according to their admission risk levels: high admission risk area (A), medium admission risk area (B), and low admission risk area (C) (fig 1). These three areas were compared with regard to a number of indicators:

(1), (2) Prevalence rates of schizophrenia and manic-depressive psychoses-These are based on the results of the study "Differential rates of psychoses in Croatia". 11 1314 They were obtained from the endogenous psychosis screening of a representative sample of the Croatian population aged 20-64 years, encompassing 23754 subjects in 95 clusters. All patients showing symptoms of 
the disease within the preceding three months were included. Those free of symptoms in the past three months, but with a previous admission and a record in the CPCR, as well as those indicated as suspect by autoanamnestic and/or heteroanamnestic data and by medical records, were designated "waiting list" (WL) and followed up for the subsequent three years. Individuals manifesting the symptoms during the observation period were diagnosed by the same criteria and also included in the prevalence rate calculation. All clusters were distributed by territorial units according to the level of admission risk areas. The prevalence was expressed per 1000 cases screened. (3) Percentage of immigrants in the place of permanent residence - These data are based on the 1971 census (population, population and flat census 1971, Federal Bureau of Statistics, Belgrade, 1975). The total population figure of a community and the number of inhabitants immigrated to a place of permanent residence in the community were summed by subregions and distributed by admission risk areas; the percentage of immigrants to the place of permanent residence within the corresponding risk area is also shown.

(4) Hospital incidence (incidence rate)-This is based on CPCR data (see Methods in Folnegovic et $a l^{1517}$ ). For the purposes of the present paper all the schizophrenic patients whose first admission was recorded in 1971 and in 1981 were identified. Only those aged $15-54$ years at the time of their first admission were included. The cases were distributed by admission risk areas according to their places of permanent residence at their first admission. The hospital incidence was expressed as a rate per 1000 inhabitants aged 15-54 years and it was age standardised.

(5), (6), (7), (8) Percentage of schizophrenic immigrants to the place of permanent residence, age of disease onset, number of the schizophrenic's

Table Some indicators of schizophrenia admission risk up to age of 31 years by area type for Croatia.

\begin{tabular}{|c|c|c|c|c|}
\hline \multirow[b]{2}{*}{ Indicators $^{\star}$} & \multicolumn{3}{|l|}{ Risk area } & \multirow{2}{*}{$\begin{array}{l}\text { Significance } \\
(A \vee \mathrm{C})\end{array}$} \\
\hline & $\operatorname{High}(A)$ & Medium (B) & $\operatorname{Low}(C)$ & \\
\hline $\begin{array}{l}\text { Schizophrenia admission risk up to } 31 \\
\text { years of age per } 1000 \text { births }\end{array}$ & 6.89 & 5.30 & 3.92 & $0.001^{\mathrm{a}}$ \\
\hline $\begin{array}{l}\text { Prevalence per } 1000 \text { population aged } 20-64 \\
\text { years for: } \\
\text { Schizophrenia } \\
\text { Manic-depressive psychoses }\end{array}$ & $\begin{array}{l}5.11 \\
1.28\end{array}$ & $\begin{array}{l}3.49 \\
1.12\end{array}$ & $\begin{array}{l}1.54 \\
0.51\end{array}$ & $\begin{array}{l}0.005^{\mathrm{a}} \\
\mathrm{NS}^{\mathrm{a}}\end{array}$ \\
\hline $\begin{array}{l}\text { Percentage of immigrants: } \\
\text { In the population } \\
\text { Of schizophrenics }\end{array}$ & $\begin{array}{l}19.2 \\
10.8\end{array}$ & $\begin{array}{l}23.1 \\
15.6\end{array}$ & $\begin{array}{l}38.5 \\
23.8\end{array}$ & $\begin{array}{l}0.001^{\mathrm{b}} \\
0.001^{\mathrm{b}}\end{array}$ \\
\hline $\begin{array}{l}\text { Age-standardised rates for incidentally } \\
\text { hospitalized schizophrenics per } 1000 \\
\text { population aged } 15-54 \text { years in: } \\
1971 \\
1981\end{array}$ & $\begin{array}{l}0.30 \\
0.34\end{array}$ & $\begin{array}{l}0.34 \\
0.32\end{array}$ & $\begin{array}{l}0.27 \\
0.32\end{array}$ & $\begin{array}{l}N_{S} S^{a} \\
N S^{a}\end{array}$ \\
\hline $\begin{array}{l}\text { Age of disease onset in schizophrenics: } \\
\text { Average age } \\
\text { Median } \\
<25 \text { th year percentage } \\
\text { positive heredity } \\
\text { negative heredity }\end{array}$ & $\begin{array}{l}22.4 \\
20.2 \\
71.2 \\
87.5 \\
58.6\end{array}$ & $\begin{array}{l}24.2 \\
21.7 \\
58.2 \\
61.5 \\
54.1\end{array}$ & $\begin{array}{l}25.7 \\
25.1 \\
48.4 \\
50.0 \\
48.3\end{array}$ & $\begin{array}{l}0.02^{\mathrm{c}} \\
0.05^{\mathrm{d}} \\
0.01^{\mathrm{b}} \\
0.01^{\mathrm{b}} \\
\mathrm{NS}^{\mathrm{b}}\end{array}$ \\
\hline $\begin{array}{l}\text { Percentage of schizophrenics with children } \\
\text { Average number of children }\end{array}$ & $\begin{array}{r}39.8 \\
2.3\end{array}$ & $\begin{array}{r}55.1 \\
2.0\end{array}$ & $\begin{array}{r}62.3 \\
2.1\end{array}$ & $\begin{array}{l}0.005^{b} \\
\mathrm{NS}^{\mathrm{e}}\end{array}$ \\
\hline $\begin{array}{l}\text { Percentage of schizophrenics with positive } \\
\text { family heredity }\end{array}$ & 21.2 & 24.7 & 22.2 & $\mathrm{NS}^{\mathrm{b}}$ \\
\hline
\end{tabular}

children, and family heredity (cases of psychiatric disorders in blood relatives with exception of patient's children) are based on the findings of the study "Use of computerized registries in followup studies". ${ }^{18}$ This study is based on a lifetime follow up of the representative sample of schizophrenic hospital inpatients. The sample was selected from a framework of 8069 CPCR recorded cases admitted to hospital during the 1962-1971 period (see Methods in FolnegovićŠmalc et $a l^{19}$ ). Cases were distributed by individual admission risk areas according to the place of permanent residence at the time of selection into the sample.

When comparing individual areas, indicators for subregion 16, the capital of Croatia ("City of Zagreb", fig 1) were excluded from the high admission risk area. This was done because we judged that the coverage of the local population by the public health service in this subregion could have a more significant impact on earlier identification of schizophrenic patients than in other subregions.

The significance of differences between particular indicators was tested by taking into consideration only the high and low admission risk areas; statistical tests applied are given in the table.

\section{Results}

In 1953, 80445 persons were born in Croatia. Of those, 464 were identified via the CPCR as having been admitted for and diagnosed with schizophrenia by the age of 31 years. The admission risk rate was found to be 5.77 per 1000 births.

It will only be possible to determine the lifetime risk of admission for the 1953 births after following them up with CPCR over the next 20 years or more. For the time being, only an estimate of the risk may be given. This can be based on the annual number of incidentally admitted schizophrenics born in Croatia and on the patient's age at incidental admission. Currently about 900 such cases are incidentally admitted to hospital annually, only slightly more than half being 31 years old or younger at the time of incidental admission. During the subsequent follow up of the 1953 births, and based on this information, the CPCR may be expected to record an additional quantity of slightly below 450 cases, which would yield an admission risk of around $1 \%$. Taking into account that about $2 \%$ of the 1953 births died by the age of 14 years (infant deaths excluded), that some moved away, and that a portion of schizophrenic persons will never be admitted to hospital in order to be diagnosed as schizophrenic, the lifetime schizophrenia risk for births in the Croatian population can be estimated to be over above $1 \%$.

Admission risk rates for schizophrenic patients up to the age of 31 years were different for births in the different subregions: they ranged from 3.4 per 1000 births in the Osijek (subregion 6 on fig 1), situated in the inland part of eastern Croatia, to 8.5 per 1000 births in the Dubrovnik area ( 2 on fig 1), in the southernmost part of the Littoral. It is necessary to point out that no closer correlation between the admission risk and the 
live birth rate per $1000(\mathrm{r}=0.0459, \mathrm{t}=0.166)$, infant deaths per 1000 live births $(r=-0.4463$, $t=-1.880$ ), nor for stillbirths per 100 live births $(r=-0.077, t=-0.278)$ was found in the 1953 births between the subregions observed $(\mathrm{df}=14$; $\mathrm{p}>0.05$ ).

Figure 1 shows subregional distribution by the level of admission risk rate.

The area of low admission risk included all subregions with the rate below 4.9 per 1000 births, medium risk with 5.0-5.9 per 1000, and high risk with 6.0 per 1000 or higher.

The table compares these three areas according to some population characteristics, morbidity indicators, and characteristics of the schizophrenic cases found in the population.

Significant differences between the high and low admission risk areas were manifested with regard to the schizophrenia prevalence, the proportion of immigrants in the place of permanent residence, the age of disease onset, and schizophrenic fertility.

The significantly higher proportion of cases with disease onset by the age of 25 years in the high risk area derived from the difference in the disease onset between cases with positive heredity in these two areas. In the high admission risk area, the proportion of cases with disease onset by the age of 25 years was significantly higher among the positive heredity cases $\left(\chi^{2}=7.50 ; \mathrm{df}=1\right.$, $\mathrm{p}<0.001$ ), whereas in the low risk area the proportion of these cases was approximately equal both in the positive and negative heredity cases $\left(\chi^{2}=0.009 ; \mathrm{df}=1 ; \mathrm{p}>0.10\right)$.

In the high risk area, the manic-depressive psychosis prevalence rate is also twice as high as in the low risk rate area. The small number of these cases found in the representative sample of the low admission risk area was also among the reasons why the difference did not prove significant. Nor did these two admission risk areas differ significantly with regard to the hospital incidence rate, to the family heredity in patients found in the population, and to the number of children among those patients who had children.

\section{Discussion}

Many epidemiological studies referred to in the introduction to this paper have shown long ago that different parts of Croatia have different prevalences of mental disease. The present study further reveals that there are differences in the admission risk for schizophrenia in schizophrenics aged up to 31 years and born within the 1953 cohort in different parts of Croatia. Higher admission risk rates were recorded in the population having a higher prevalence of schizophrenia as well as of manicdepressive psychoses. The findings further indicate that even despite the differences in the admission risk rate the incidence rate in these areas is roughly equal, thus raising the question as to why the incidence of schizophrenia in the population of Croatia is constant. To answer this point our effort focused mainly on observing the following factors: (1) those essential for the prevalence and admission risk for schizophrenia being different in different parts of Croatia; (2) those that keep the schizophrenia incidence constant in populations with different schizophrenia prevalences and different schizophrenia admission risks.

Differences in schizophrenia prevalence and admission risk for schizophrenia were analysed from several points of view. The first aspect related to detecting a correlation between schizophrenia admission risk and overall birth rate, stillbirths, and infant mortality for the 1953 births in the observed subregions of Croatia, but none of these variables was found to be associated to any significant degree.

The second aspect related to the question of the potential influence that the development of psychiatric services and case identification might have on the admission risk rate and on prevalence rate. In the high prevalence and high admission risk area, one finds both a subregion with a developed psychiatric service and a relatively large number of psychiatric beds (eg, the Zadar subregion 14; fig 1) and the Lika subregion (5), which is the least developed of all Croatian subregions and has the fewest psychiatric beds. Moreover, endogenous psychosis screening in Croatia has revealed that $16^{\circ}$ of schizophrenic patients have not been in hospital $(0.55$ per $1000)^{20}$ by the time of screening, and that the proportion of cases that had not been admitted to hospital was roughly equal among areas with different admission risks and rates of prevalence. Based on the above it could be inferred that the differences in the admission risk rates and prevalence rates among individual areas in Croatia were not significantly affected by the level of psychiatric service development and by the number of psychiatric beds. The level of service development could lead to a possible shortening of the preadmission stage, of postadmission treatment, and of relapse frequency, but it may not affect the final case identification, particularly since "prevalence" in the present study was defined as "patients who have ever been ill at any time in their lives".

The third aspect related to establishing whether some clinical and social case characteristics from individual areas influence the observed differences in the admission risk and prevalence rates. This primarily refers to differences in the age of disease onset and case prognosis. The results of a lifelong follow up of a representative sample of admitted schizophrenics (see Methods in Folnegović-Šmalc et $a^{19}$ ) in Croatia indicate that patients from the high admission risk and high prevalence rate area have an earlier age of onset (an analysis of the 1988-1990 data is in preparation). In this connection higher admission risk rates up to the age of 31 years could be due to a larger number of cases with an earlier disease onset, while higher prevalence rates might also result from the anticipated longer duration of disease in that population. The results of the lifelong case follow up in the high admission rate and higher prevalence rate area further show that, apart from the disease having an earlier onset at a younger age, its patients also have a poorer clinical, social, and life expectancy. They more frequently remain single, without a family of their own, and are more often without their own source of income. Furthermore suicide is more common among them, and they also die more frequently at 
a younger age of other preventable diseases. It is for this reason, and despite the earlier disease onset, that the average duration of illness of the patients found in these areas with different rates of prevalence does not differ to a larger degree. Consequently, disease onset age differences are explainable by the differences in admission risk, though the significant differences in prevalence rates between individual areas in Croatia cannot be explained in this way.

The analysis of differences in admission risk and prevalence rates between individual areas in Croatia could not be said to have revealed factors which would contribute much to an explanation of the observed differences in prevalence rates, and particularly not that for differences in the age of disease onset.

The fourth aspect related to observing a possible influence of population migration on the differences in schizophrenia prevalence and admission risk in some areas. The fact that the population at higher admission risk had a significantly larger proportion of persons born in the place of permanent residence provided an incentive to examine this. Also important was the fact that Croatia is a country with a high rate of economic emigration which began at the dawn of the century. First this emigration was mainly to the USA, but later to other overseas countries. ${ }^{21}$ With varying intensity in different periods, this process has continued uninterruptedly to date. Furthermore, in comparison with other Yugoslav republics Croatia has had the lowest annual population increment ${ }^{21}$ during the observation period 1921-1971. Croatian losses during the second world war were also significant. ${ }^{22}$ Internal population migrations only became more extensive after the war. ${ }^{23}$

Since there are interregional differences in Croatia with regard to the intensity, time, and type of migration, several basic migration characteristics are presented for populations carrying unequal admission risks for schizophrenia.

The high admission risk area is characterised by a continuous, almost century-long emigration, mostly towards overseas countries, except for the Vinkovci subregion (13, fig 1). Though most noticeable on islands, emigration is also present in other subregional populations of this area. Many insular settlements, as well as the Island of Susak mentioned above, have emigrant populations exceeding their current insular populations. For the observation period since 1880 this admission risk area also had the lowest population increment, ${ }^{21}$ resulting in the highest proportion of the autochthonous population today. Added to this, internal emigration occurred immediately after World War II, when the fertile Panonian plain in the north of Yugoslavia was colonised, ${ }^{24}$ often producing a break up of clans, with individual families and even portions of settlements leaving the high risk area. The largest group has settled in the Vinkovci subregion where a high schizophrenia admission risk was also reported for newcomer births.

Diverse migratory processes were taking place in some parts of the medium admission risk area. While its continental part was free of any larger emigration or immigration, the Istrian peninsula
(3, fig 1) and Rijeka (7) subregions witnessed very intensive migratory processes. The overseas emigration, begun at the beginning of the 20th century, intensified between the two world wars, and immediately after the second world war. ${ }^{21}$ Due to the strong development of tourism in these regions after the war, the area now receives a mostly younger, active working population from all over the country. Greater immigration to this area (study area) in which a higher schizophrenia prevalence rate had been established previously, may be linked to the previously mentioned decrease in the incidence and prevalence of schizophrenia in the recent years.

The low admission risk area happens to lie in a part of the fertile Panonian plain which attracted the previous waves of economic immigration. The abandoned estates in the immediate post-World War II period were settled by families from different parts of the country, which also led to the fact that this area now has the smallest proportion of autochthonous population.

Such migratory processes in the areas with different admission risks indicate that the prevalence of schizophrenia is associated with population migrations to a remarkable extent. Most succinctly, it could be described using the following relations:

The higher prevalence rate is manifested in a population characterised by intensive economic emigration and a greater proportion of the autochthonous population.

The medium prevalence rate is expressed in a population having a weakly expressed migration, and in a population showing intensive economic emigration, but also undergoing immigration.

The low prevalence rate is manifested in a population with intensive immigration and a lower proportion of antochthonous population.

The variation in schizophrenia admission risk between certain areas of Croatia suggests that economic migration may be the most important determining factor. On the other hand, in reviewing factors which keep the incidence of schizophrenia roughly equal and constant even in populations with different schizophrenia prevalence and admission risk, the focus was chiefly on examining individual characteristics of schizophrenic patients in those populations.

Differences were thus noted in the age of disease onset between schizophrenic inhabitants of individual admission risk areas. Age difference in the disease onset among the cases in high and low schizophrenia admission risk areas were manifested in cases with positive family heredity only. Since disease onset occurs at an earlier age in cases with positive heredity, and thus it also occurs earlier in a population with higher schizophrenia prevalence, this points to a link between the changing of characteristics of the schizophrenic disease and the level of a population's hereditary loading. The fact that cases born in the Vinkovci subregion (13), but of parents having immigrated there from areas with a high schizophrenia prevalence, retain the same disease onset and admission risk characteristics as the population from which they had emigrated points in that direction. So an earlier disease onset 
in schizophrenia cases with positive heredity could be an indicator of a heavier hereditary loading in the population.

This knowledge might increase our understanding of the risk of schizophrenia development among emigrant offspring, which has been the subject of contradictory reports. Thus, Eaton ${ }^{25}$ has stated that there have been many studies of the relationship of immigration to the risk for schizophrenia, with some studies showing a higher risk for immigrants, but others revealing no higher risk. According to the present study findings, these differences would be a reflection of the differences in the risk for schizophrenia between the populations of migratory origin. When related to disease onset differences between individual admission risk areas in Croatia, reproduction differences among the schizophrenic patients in those areas also become comprehensible. Thus in the high admission risk areas significantly fewer schizophrenics have children. Those who do have on average about as many children as do the cases from the low admission risk area, something that would approximate the child expectancy in the general population segment of the same age. ${ }^{26}$ There have been many reports ${ }^{27-30}$ of such characteristics. This fits in with the claim that the lower reproduction of schizophrenia patients is a consequence of not marrying rather than of the reduced fertility, ${ }^{31}$ since in our population, reproduction is also primarily related to marriage. Concerning the association between schizophrenic persons entering a marriage and the disease onset in the population of Croatia, Folnegović-Šmalc ${ }^{32}$ has emphasised that the majority of cases will remain single if the onset of their disease coincides with the age when the majority of the population marry, or if it occurs earlier; if the onset of the disease intervenes after that age, there will be no

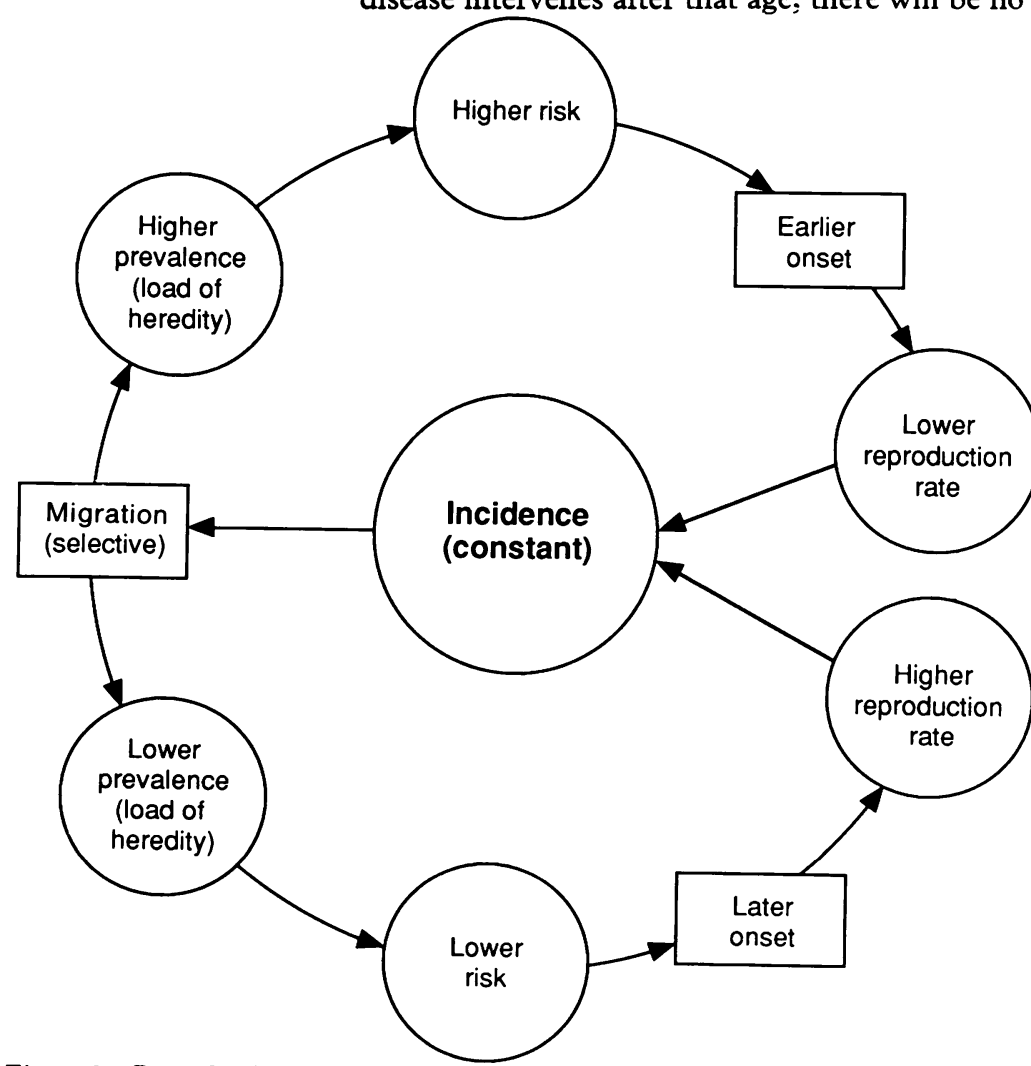

Figure 2 Reproductive cycle of schizophrenia in the population greater difference as to a marriage between the schizophrenic person and someone from the "general population". Shmaonova et al ${ }^{33}$ have also stressed the big influence of the marriage age on infertility. Bland and Orn ${ }^{34}$ and Odegard ${ }^{35}$ have also shown prepsychotic fertility to be higher than post-psychotic fertility. Standardised rates for unmarried schizophrenic male and female patients (according to the age pattern of the unmarried in the general population of Croatia) show that in schizophrenic patients the unmarried rate for males is higher than for females. ${ }^{32}$ As schizophrenic males and females do not differ significantly by age of disease onset, ${ }^{19}$ the larger proportion of females that get married may be ascribed to the fact of their marrying at a younger age and thus having a greater chance to marry before the onset of the disease. This could also explain the greater reproduction in schizophrenic females than males, or in other words the higher frequency of the positive heredity in cases stemming from mother than from father.

The lower schizophrenic reproduction rate in the high admission risk area might then be a consequence of the fact that the onset of the disease in a major part of cases with positive heredity starts earlier, ie, at an age before that at which persons from the "general population" marry. Thus, Book ${ }^{36}$ has also linked the decrease in the number of marriages in an isolated population to the rise in earlier case admissions from a younger cohort. This shows that within a population with a greater prevalence of schizophrenic persons and with a larger share of autochthonous inhabitants, patients with positive heredity experience a diminished reproduction due to an earlier onset of the illness. This fetters the reproduction of those persons who would be at the highest risk of becoming ill from schizophrenia owing to their positive heredity. Since in the population with a smaller prevalence the schizophrenic patients with positive heredity experience the onset of the illness at a later age, reproduction is greater in these patients. Therefore, the portion of schizophrenics with positive heredity who are found in populations with different prevalence rates and different "admission risk" rates is roughly the same. In this way, incidence rates are kept roughly the same over generations. Figure 2 gives the most basic outline of the reproduction cycle of schizophrenia in populations with different prevalence.

Nevertheless, under the influence of selective migrations prevalence and incidence rates may for a period change in some areas. This is in agreement with Torry's ${ }^{37}$ finding based on more than 70 prevalence studies of schizophrenia published since 1948, that "the studies suggest that there may be significant differences in prevalence among different populations and that prevalence may change over time"'. Such changes have also been observed in Croatia, ie, in the subregions of Istria (3) and Rijeka (7) (fig 1), where the decrease in incidence and prevalence rates in the past three decades is linked to a higher immigration of younger active working population. The decrease in incidence rates over the past decades in New Zealand ${ }^{38}$ could also be accounted for in the light of the above aspects. 
Also, several studies in West European countries indicate that the incidence rate of schizophrenia may be declining, especially in the past two decades. ${ }^{39-43}$ As this decline cannot be attributed to changes in diagnosis or to improvement in care, ${ }^{44-46}$ it has been examined in the light of changes in aetiological factors. ${ }^{47-50}$ This is primarily linked with the increase in the prevalence of schizophrenia and the more frequent occurrence of schizophrenia with an early onset in the west European countries during the 19th century, ${ }^{45}$ as well as with the decline in the incidence rate during the recent decades in these countries, especially in the younger age segments of the population. ${ }^{434551}$

In the light of epidemiological studies performed in Croatia one could raise the question as to whether the increase in the prevalence of schizophrenia during the 19th century in some West European countries was not primarily a consequence of a considerable emigration of the local population overseas. In this way, the autochthonous population with a larger share of mentally ill persons also saw an increase in hereditary loading over generations, with a more frequent occurrence of a type of schizophrenia characterised by early onset. In keeping with this, the above mentioned changes in incidence, age of onset, and diagnosing structure could also be observed in the light of the hypothesis that promotes the idea of weakening of the hereditary loading in these types of populations.

Therefore, in order to understand changes in the aetiological factors, schizophrenia should be observed in a stable population; the observations should be performed over at least two generations, so that possible secular changes can be eliminated.

\section{CONCLUSION}

The risk of schizophrenia development for persons born in a family with negative heredity is about equal. This risk is increased for persons born in a family with positive heredity depending on family aggregation. It is even greater, depending on the degree of consanguinity, in persons born in a population with a heavier hereditary load. Besides, patients with a double hereditary load, ie, in the family and in the population, face the onset of the illness more often at a younger age, which makes reproduction diminish in these patients. Thus, in spite of their greater risk of becoming ill, an equilibrium is established among patients with a positive heredity within a population in which hereditary loading is decreased, owing to a lower reproduction rate among these individuals. In this way, the incidence of schizophrenia is kept roughly the same and constant over generations in populations with different prevalences and different hereditary loading.

1 Crocetti GM, Kulčar Ž, Kesić B, Lemkau PV. Selected aspects of the epidemiology of schizophrenia in Croatia
(Yugoslavia). Milbank Memorial Foundation $Q$ 1964; 42: 9-37.

2 Crocetti GM, Kulčar Ž, Kesić B, Lemkau PV. Differentia rates of schizophrenia in $\mathrm{Cr}$

Huliž 1964; S4: 196-206. Kuljzenko A. Statistika o duserivenih rezultata (Patients in za godinu 1930. te znac Yoslavia in 1930 and the meaning the mental hospitals of Yugoslavia in 1930 and the mean pet godina osvjetljena medicinskom statistikom. (Stenjevec hospital statistics 1927-1932). Glasnik Centralnog higijenskog zavoda (Beograd) 1933; 10: 8-70.

4 Lemkau PV, Kulčar Ž, Crocetti GM, Kesić B. Selected aspects of the epidemiology of psychoses in Croatia, Yugoslavia. I. Background and use of psychiatric hospital statistics. Am f Epidemiol 1971; 94: 112-7.

5 Crocetti GM, Kulčar Ž, Kesić B, Stanetti F, Lemkau PV. Testing the hypothesis against hospital statistics. In: Kesić B, Kulcar Z, Lemkau PV, eds. Epidemiology of psychoses in
Croatia. Rad. Knjiga 392. Zagreb: Jugoslavenska akademija zroatia. Rad. Knjiga 392. Zagreb: Jug

6 Geratovic I. Problem nasljedja kod shizofrenih-Bolesnici od shizofrenije na otoku Krku. Lijec vjes 1933; 12: 593-604.

7 Lopašić R, Mikić F. Duševne poremetnje na otoku Susku (Mental disorders on the Island of Susak). Fugoslavenska akademija znanosti $i$ umjetnosti, Zagreb 1957: 535-45.

8 Kulčar Z, Crocetti GM, Lemkau PV, Kesic B. Selected aspects of the epidemiology of psychoses in Croatia (Yugoslavia). II. Pilot studies of communities. $\mathrm{Am} \mathcal{F}$ Epidemiol 1971; 94: 118-25.

9 Kulčar Ž. Crocetti GM, Lemkau PV, Kesić B. Development of methods for community surveys and the results of pilot studies. In: Kesić B, Kulčar Ž, Lemkau PV eds. Epidemiology of psychoses in Croatia. Rad. Knjiga 392. Zagreb: Jugoslavenska akademija znanosti i umjetnosti, 1981: 45-56.

10 Lemkau PV, Kesić B, Gjurgjević T. The plan and setting of the study. In: Kesić B, Kulčar Ž, Lemkau PV, eds. the study. In: Kesic B, Kulcar Z, Lemkau PV, eds. Epidemiology of psychoses in Croatia. Rad. Knjiga 392. Zagreb: Jugosia

11 Bedenić B, Kesić B, Korbar M, et al. Differential rates of psychoses in Croatia. Final Report PL 480 02-276-2. Zagreb: Andrija Stampar School of Public Health, Medical Faculty University of Zagreb, 1972.

12 Bedenić B, Folnegović-Śmalc V, Kulčar Z. The Cluster Sample of the Population of Croatia: survey report. In: Kesić B, Kulčar Ž, Lemkau PV, eds. Epidemiology of psychoses in Croatia. Rad. Knjiga 392 . Jugoslavenska akademija znanosti i umjetnosti, Zagreb, 1981: 68-76.

13 Lemkau PV, Kulčar Ž, Kesić B, Kovačić L. Selected aspect of the epidemiology of psychoses in Croatia, Yugoslavia.
IV. Representative sample of Croatia and results of the IV. Representative sample of Croatia and
survey. $A m$ F Epidemiol 1980; 112: 661-74.

survey. Am f Epidemiol 1980; 112: 661-74.
14 Kesic B, Kulčar Z, Kovačić L, Lemkau PV. Major results Kesic B, Kulčr Z, Kovačić L, Lemkau PV. Major results and their interpretation. In: Kesic B, Kulčar Z, Lemkau PV eds. Epidemiology of psychoses in Croatia. Rad. Knjiga 392. Zagreb: Jugos

15 Folnegović $Z$, Folnegović-Śmalc V, Kulčar Ž. The incidence of schizophrenia in Croatia. Br $\mathcal{f}$ Psychiatry 1990; 156: 363-5.

16 Folnegović Z, Folnegović-Šmalc V, Kulčar Ž. The epidemiology of schizophrenia in Croatia-Trends in the hospitalization of schizophrenic patients in different communities. Liječ vjes 1983; 105: 385-90.

17 Folnegović Z, Folnegović-Šmalc V, Kulčar Z. Characteristics of male and female schizophrenics at first admission. Br F Psychiatry 1990; 156: 365-68.

18 Kulčar Ż, Folnegović-Šmalc V, Folnegović Z, et al. Use of computerized case registers in follow-up studies. Final computerized case registers in follow-up studies. Final of Croatia, 1983 .

19 Folnegović-Smalc V, Folnegović Z, Kulčar Ž. Age of disease onset in Croatia's hospitalised schizophrenics. $B r \mathcal{F}$ Psychiatry 1990; 156: 368-72.

20 Folnegović-Šmalc V, Folnegovič Z, Kulčar Z Nehospitalizirani shizofreni bolesnici u SR Hrvatskoj. In Kecmanović D, Loga S eds. Psihijatrija. VI kongres neurologa $i$ psihijatara fugoslavije. Sarajevo, 1980: 169-70.

21 Friganović M. Demografija: Stanovništvo svijeta. Zagreb; Školska knjiga, 1978.

22 Žerjavić V. Gubici stanovništva fugoslavije u drugom svjetskom ratu. Zagreb: Jugoslavensko viktimolosko svjetskom ratu.

23 Breznik D. Demografija: Analiza, metodi i modeli. Beograd: Naučna knjiga, 1980

24 Obradović S. Unutrašnja migracija Jugoslavije od 19181953. godine. Ekonomist 1955; 2: 10-8.

25 Eaton WW. Epidemiology of schizophrenia. Epidemiol Rev 1985; 7: 105-26.

26 Breznik D, Mojic A, Rašević M, et al. Fertilitet stanovništva u fugoslaviji. Beograd: Institut društvenih nauka, 1972.

27 Hilger T, Propping P, Haverkamp F. Is there an increase of reproductive rates in schizophrenics? Arch Psychiatr Nervenkrankenheiten. 1983; 233: 177-86

28 Erlenmeyer-Kimling L. Fertilite des psychitiques. Demographie Confrontations Psychiatriques 1978; 16: 47-81.

9 Stevens BC. Marriage and fertility of women suffering from Stevens BC. Marriage and fertility of women suffering from schizophrenia or affectiv
University Press, 1969.

30 Slater E, Hare EH, Price JS. Marriage and fertility of psychiatric patients compared with national data. In: psychiatric patients compared with national data. In: Gottesman II, Erlenmeyer-Kimling $\mathrm{L}$, eds. Fertility and
reproduction in physically and mentally disordered reproduction in physically and mentally disorder
individuals. Soc Biol 1971; Supplement 18: S60-73.

31 Saugstad LF. Social class, marriage and fertility in schizophrenia. Schizophrenia Bull 1989; 15: 9-41.

32 Folnegović-Ŝmalc V. Role of marital status in the course of schizophrenic disorders. Socijalna psihijatrija 1979; 7 233-319. 
33 Shmaonova LM, Liberman YI, Panicheva EV, et al. Family formation by patients with schizophrenia and manicdepressive psychosis based on the results of an epidemiological study of birth rates. Zhurnal Nevropatologii i Psikhiatrii SS Korsakova 1976; 75: 754.

34 Bland RC, Orn H. Fourteen-year outcome in early schizophrenia. Acta Psychiatr Scand 1978; 58: 327-38.

35 Odegard $O$. Fertility of psychiatric first admissions in Norway 1936-75. Acta Psychiatr Scand 1980; 62: 212-20.

6 Book JA. A genetic and neuropsychiatric investigation of North Swedish population. Acta Genet Med Stat 1953; 4 North

37 Torrey EF. Prevalence studies in schizophrenia. $\mathrm{Br} f$ Psychiatry 1987; 150: 598-608.

38 Joyce PR. Changing trends in first admissions and Joyce PR. Changing trends in first admissions and readmission for mania and schizophren

39 Eagles JM, Whalley LJ. Decline in the diagnosis of schizophrenia among first admissions to Scottish mental schizophrenia among first admissions to Scottish mental hospital.

40 Dickson WE, Kendell RE. Does maintenance lithium therapy prevent recurrences of mania under ordinary clinical conditions? Psychol Med 1986; 16: 521-30.

41 Munk-Jorgensen P. Decreasing first admission rates of schizophrenia among males in Denmark from 1970 to 1984 changing diagnostic patterns? Acta Psychiatr Scand 1986 73: $645-50$.
42 Munk-Jorgensen P, Jorgensen P. Decreasing rates of first admission diagnoses of schizophrenia among females in Denmark 1970-1984. Acta Psychiatr Scand 1986; 74: 379-83.

43 Der G. Gupta S, Murray R. Is schizophrenia disappearing? Lancet 1990; 335: 513-6.

44 Stromgren E. Changes in the incidence of schizophrenia? $\mathrm{Br}$ f Psychiatry 1987; 150: 1-7.

45 Hare E. Schizophrenia as a recent disease. Br $\mathcal{f}$ Psychiatry 1988; 153: 521-31.

46 Eagles JM, Hunter D, McCance C. Decline in the diagnosis of schizophrenia among first contacts with psychiatric services in North-East Scotland, 1969-1984. Br $\mathfrak{J}$ Psychiatry 1988; 152: 793-8.

$47 \mathrm{Hare}$ EH. Schizophrenia as an infectious disease. $\mathrm{Br} \mathcal{F}$ Psychiatry 1979; 136: 468-73.

48 Hare EH. Was insanity on the increase? Br $\mathcal{f}$ Psychiatry 1983; 142: 439-55.

49 Crow TJ. Is schizophrenia an infectious disease? Lancet 1983; i: 173-5.

50 Reveley AM, Reveley MA, Murray RM. Cerebral Reveley AM, Reveley MA, Murray RM. Cerebral
ventricular enlargement in non-genetic schizophrenia. Brf

51 Bleuler M. The schizophrenic disorders: long-term patient and family studies (translated by S M Clemens). New Haven: Yale University Press, 1978.

OF THE PRESENT DISPOSAL OF THE NIGHT SOIL

Of one of these night-yard factories Dr Gavin gave, in 1848, the following account:-

"On the western side of Spitalfields workhouse, and entering from a street called Queen Street, is a nightman's yard. A heap of dung and refuse of every description, about the size of a tolerably large house, lies piled to the left of the yard; to the right is an artificial pond, into which the contents of cesspools are thrown. The contents are allowed to dessicate in the open air; and they are frequently stirred for that purpose. The odour which was given off when the contents were raked up, to give me an assurance that there was nothing so very bad in the alleged nuisance, drove me from the place with the utmost speed.

"On two sides of this horrid collection of excremental matter was a patent manure manufactory. To the right in this yard was a large accumulation of dung, \&c., but to the left there was an extensive layer of a compost of blood, ashes, and nitric acid, which gave out the most horrid, offensive, and disgusting concentration of putrescent odours it has ever been my lot to be the victim of. The whole place presented a most foul and filthy aspect, and an example of the enormous outrages which are perpetrated in London against society.

"It is a curious fact, that the parties who had charge of these two premises were each dead to the foulness of their own most pestilential nuisances. The nightman's servant accused the premises of the manure manufacturer as the source of perpetual foul smells, but thought his yard free from any particular cause of complaint; while the servant of the patent manure manufacturer diligently and earnestly asserted the perfect freedom of his master's yard from foul exhalations; but considered that the raking up of the drying night-soil on the other side of the wall was 'quite awful, and enough to kill anybody'.

"Immediately adjoining the patent manure manufactory is the establishement of a bottle merchant. He complained to me in the strongest terms of the expenses and annoyances he had been put to through the emanations which floated in the atmosphere having caused his bottles to spoil the wine which was placed in such as had not been very recently washed. He was compelled frequently to change his straw, and frequently to wash his bottles, and considered that unless the nuisance could be suppressed, he would be compelled to leave his present premises."

This and similar places were suppressed soon after the passing of the sanitary measures of September, 1848.

The cesspool refuse, which was disposed of for manure, was at that time first shot into recesses in the night-yard, where it was mixed with exhausted hops procured from the brewhouses, which were said to absorb the liquid portions, when stirred up with the matter, and to add not only to the consistency of the mass, but to its readier portability for land manure or for stowage in a barge. It was also mixed with littered straw from the mews, and with stable manure generally. An old man who had worked many years - he did not know how many - in one of these yards, told me that when this night-soil was "fresh shot and first mixed" (with the hops, \&c.), the stench was often dreadful. "How we stood it," he said, "I don't know: but we did stand it."

London Labour and the London Poor; a cyclopaedia of the conditions and earnings of those that will work, those that cannot work, and those that will not work by Henry Mayhew, 1861 